\title{
Evaluation of Nutrition and Eating Habits in Children and Adolescents Practicing Football in a Sports Club in Bydgoszcz, Poland
}

\author{
Monika Ameryk, Małgorzata Pujanek, Agnieszka Augustyniak, Małgorzata Szamocka and Maciej Świątkowski \\ Department of Gastroenterology and Nutrition Disorders, Collegium Medicum in Bydgoszcz, Nicolaus Copernicus University in \\ Toruń, Bydgoszcz 85-168, Poland
}

\begin{abstract}
Proper diet is important for children and adolescents practicing sports, providing nutrients for the correct growth, optimal performance and recovery. Therefore, this study evaluated the diet and eating habits of children and adolescents practicing football. One hundred boys (aged 11 16) are involved in the study. Eating habits and consumption of 33 products were assessed using a modified KomPAN questionnaire. Subsequently, indices of healthy and unhealthy diet were determined. Only $30 \%$ respondents ate five meals per day and $16 \%$ kept fixed meal times. Almost $30 \%$ had a snack once daily, $90 \%$ ate fast food once a week, and $88 \%$ added sugar to beverages. One in ten ate sweets several times per week, while $20 \%$ - once daily. $86 \%$ ate fish once a week. $52 \%$ and $4 \%$ ate white and dark bread several times per day. Only $20 \%$ had buckwheat several times per week. White and red meat was eaten several times per week by $66.3 \%$ and $35.6 \%$, while fish by only $5.7 \%$. Only $20 \%$ had a moderate index of healthy diet and $90 \%$ had a low index of unhealthy diet. It is concluded that education of young footballers in nutrition is necessary to correct their eating habits and improve physical performance.
\end{abstract}

Key words: Young athletes, football, nutrition, eating habits, dietary behaviours.

\section{Introduction}

Football is the most widely-practiced sports discipline in the world and the most popular one among children and adolescents in Poland. The main objective of the many years of training children and adolescents is the systematic transfer of talented and fully formed players to adult teams. Training of young footballers involves not only developing their talent, but also teaching and improving their specific football skills, such as technique, speed, motor coordination and desired personality traits. There are other conditions for children and adolescents that need to be satisfied in order to achieve success in football. Among the primary conditions are the appropriate didactic and sports facilities along with competent teachers and trainers assisted by physiologists, psychologists,

Corresponding author: Monika Ameryk, M.Sc., research field: sport nutrition for young athletes. biological regeneration specialists, managers and nutritionists. In light of these circumstances arising from the general education in Poland, three stages of football training can be identified. The first comprehensive stage includes children aged $7 \sim 12$ years attending elementary school, the second specialized stage includes adolescents aged 13 18 years, and the third adult stage includes adults from 19 years of age until the end of career [1]. Moreover, the nomenclature and letter coding of football training categories in Poland refers to the various training categories identified by the UEFA (Union of European Football Associations), e.g., age 10 11 (“Orlik"): E1, age 12 13 ("Młodzik"): D1, age 15 16 ("Junior Młodszy"): B2 [1]. Children and adolescents practicing sports, including football, are a population with special nutritional requirements. The intense physical activity and development associated with football training cause increased demands for 
energy and essential nutrients: proteins, carbohydrates, fats, vitamins, minerals and water. Children and adolescents have much higher energy requirements per $\mathrm{kg}$ b.w. (body weight) than adults, and an additional energy expense of $20 \sim 30 \%$ compared to adult athletes is observed in association with training and sports events [2]. Repeated low calorie supply may result in not only reduced athletic development, but also malnutrition, increased susceptibility to diseases, increased risk of injuries, reduced growth and delayed puberty [3-5]. Depending on the intensity and duration of physical effort, carbohydrates should cover from $45 \%$ to $65 \%$ of total energy demand of a child. Although carbohydrates stored as glycogen are the main source of energy for active muscle fibers, a young organism uses a higher amount of energy from the oxidation of fatty acids. This may result in a lower demand for carbohydrates in young football players compared to adults [6,7]. Although there is no difference in protein metabolism between adults and children/adolescents, the latter group demonstrates an increased demand for proteins associated mainly with body growth. The increased protein catabolism and the process of regeneration of damaged muscle structures associated with endurance training and basic strength training increase the demand for proteins up to $1.2 \sim 1.4 \mathrm{~g} / \mathrm{kg}$ b.w. It is recommended that the protein supply in young sportsmen cover $10 \sim 30 \%$ of the overall calorie demand [8-10]. In turn, fats should cover from $25 \%$ to $35 \%$ of calorie demand (including up to $10 \%$ covered by saturated fats). It is important to supply polyunsaturated fatty acids, particularly omega-3, which should be provided in quantities of more than $250 \mathrm{mg} /$ day. Trans fatty acids should be eliminated [11, 12]. In children and adolescents practicing intense physical activity associated with sports, it is more likely to observe dehydration and overheating than in adults due to the immature thermoregulatory mechanisms, lower perspiration, greater body surface area to body weight ratio and drinking insufficient amount of fluids. Daily water demand in boys between 10 and 18 years of age is from $2,100 \mathrm{~mL}$ to $2,500 \mathrm{~mL}$. In the period of training or during sports events, additional fluid supply is necessary. Providing beverages to young sportsmen allows delaying the rise of fatigue and improving the ability to withstand physical effort [13-15]. The Polish National Food and Nutrition Institute in 2016 proposed a healthy eating pyramid for school-age children and adolescents, including those practicing intense physical activity, while the Swiss Society for Nutrition in 2008 presented a food pyramid for athletes [16]. There is no Polish standard of nutrition for either child, adolescent or adult athletes. However, in light of the above mentioned publications and the known differences in the metabolism in children and adults, rational nutrition of children and adolescents practicing sports can be recommended. The diet of young sportsmen should also combine the nutrition recommendations for developing age groups and the recommendations for children and adolescents practicing intense physical activity. The diet should be varied and include products of each level of the pyramid [17]. Nutrition should be based on vegetables and fruits in at least three and two daily portions, respectively. These products are a rich source of vitamins, minerals and fiber, and due to their alkalizing properties, they support the restoration of the acid-base balance by the physiological buffering systems, as well as the restoration of homeostasis after physical effort [18]. Cereal products, particularly those made of whole grain, are an important source of carbohydrates and should be one of the main sources of energy, served in five portions per day [8]. It is recommended to consume at least four portions of milk or dairy products, such as buttermilk, kefir, yoghurt and cheese, which are the source of complete protein and biologically available calcium, very important for the developing age groups [17, 19]. Products constituting a source of protein, such as meat, fish, eggs and legume seeds, should be consumed by children and adolescents in two portions per day. Special attention should be paid to the consumption of meat as it is also 
an essential source of biologically available iron. Nutrition studies often reveal insufficient supply of iron in the diet of children and adolescents, since in these developing age groups often practicing intense physical activity the demand for iron is significantly increased [8, 17]. Fish play a very important role in the nutrition of young sportsmen and should be consumed twice a week. Fish are rich in complete protein, Vitamin $\mathrm{D}_{3}$, iron, iodine and, above all, omega-3 polyunsaturated fatty acids that are important for the metabolism in children and adolescents. Fats are another important group of nutrition products [8]. In sportsmen nutrition, it is recommended to use high quality vegetable oils, olive oil and nuts that contain omega- 3 and omega- 6 fatty acids, while it is also recommended to limit the intake of saturated animal fats, trans isomers of unsaturated fatty acids (present in fast food, pastries, biscuits and chocolate), as well as hydrogenated vegetable oils [17]. A composition of five varied meals per day that would include products from all levels of the food pyramid is the basis for the rational nutrition of young sportsmen [16]. Rationalized nutrition is one of the essential factors contributing to achieving good results in sports and the basis for the proper body development, functioning of organs and systems, and increasing the physical capacity desired in sports [20].

\section{Materials and Methods}

The study group consisted of 100 boys aged 11 16 practicing football in the sports club in Bydgoszcz, Poland. Accompanied by their parents, the respondents answered questions about their nutrition. Eating habits and the frequency of consumption of 33 products were assessed using the modified KomPAN questionnaire, Parts A and B. The results were analyzed based on the publication "Procedury danych żywieniowych $z$ kwestionariusza KomPAN" (Processing Data from the KomPAN Questionnaire) [21]. The questionnaire also assessed the quality of the diet. To this end, two indices were adopted: "healthy diet index" and "unhealthy diet index". The indices were calculated by summing the frequency of consumption (times/day) of 10 and 14 groups of products, respectively. The interpretation of the indices is intuitive: the larger the index value, the more favorable or unfavorable characteristics of the diet. The quality of nutrition and the frequencies of consumption of each product were analyzed using the Statistica 12.5 software.

\section{Results and Discussion}

The study revealed (Fig. 1) that $29.2 \%$ of the young players ate five meals per day, while $11.2 \%$ of them ate only three meals per day.

It was also found (Fig. 2) that $15.7 \%$ of the respondents ate meals at fixed times, while for $77.5 \%$ only some meals were eaten at fixed times.

Eating between meals was one of the reported negative nutritional habits (Fig. 3) and occurred once daily in $29.2 \%$ of the respondents and several times a day in $16.9 \%$ of the respondents. Eating between meals more than once a week was reported by $80 \%$ of the respondents. The other boys $(2.3 \%)$ were excluded due to the choice of more than one answer.

The most popular snack (Table 1) were fruits $(63 \%)$, followed by sweet snacks (58\%). The least popular

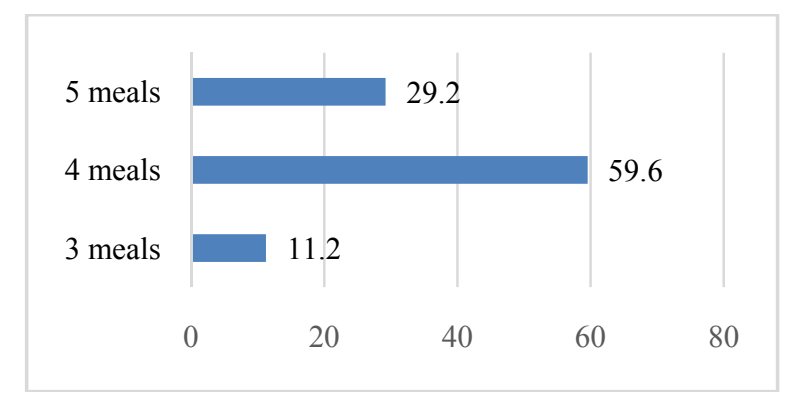

Fig. 1 Eating frequency.

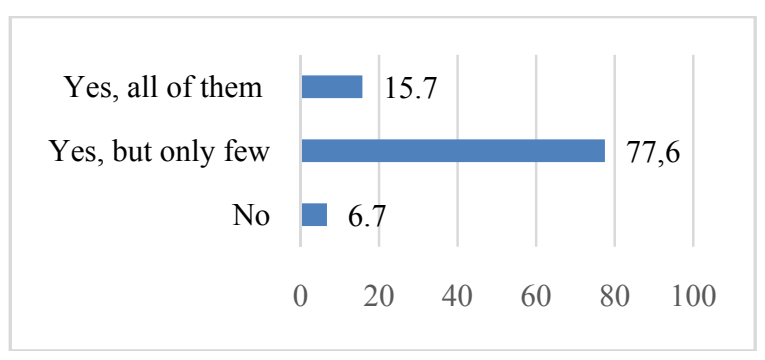

Fig. 2 Consumption of meals at fixed times. 

Practicing Football in a Sports Club in Bydgoszcz, Poland

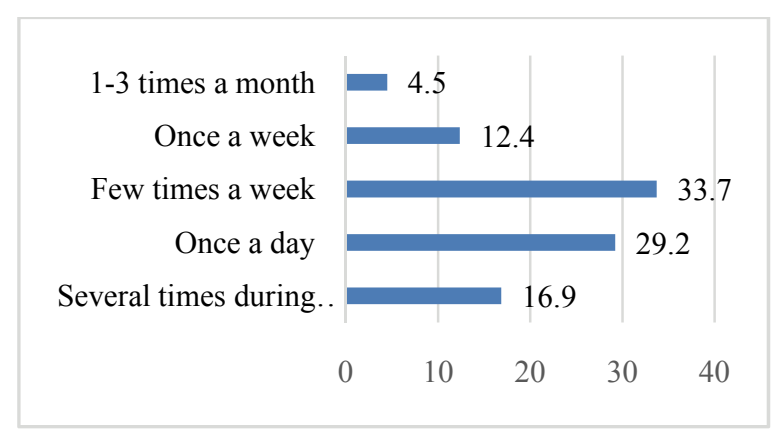

Fig. 3 The frequency of eating between meals.

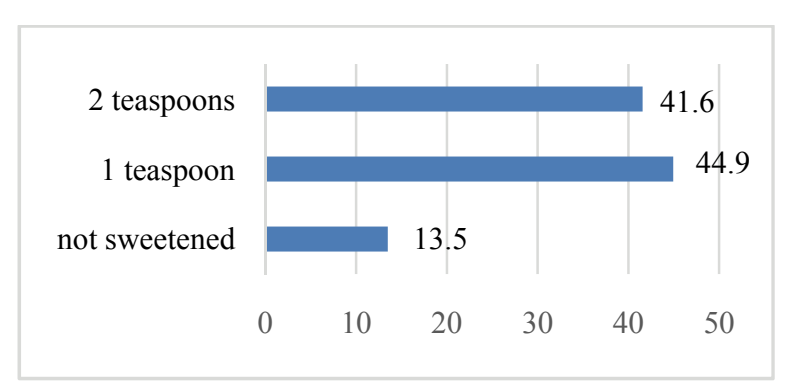

Fig. 4 Adding sugar to beverages.

snack were nuts, almonds, seeds, etc. (17\%).

The study also demonstrated (Fig. 4) a high consumption of sugar used to sweeten beverages. Two teaspoons of sugar $(10 \mathrm{~g})$ were reported by $41.6 \%$ of the respondents, while one teaspoon ( $5 \mathrm{~g}$ ) was reported by $44.9 \%$ of the respondents. Only $13.5 \%$ of the respondents did not add sugar to their beverages at all.

Analysis (Fig. 5) showed that the most popular cereal product was white bread, eaten at least once a day by $73 \%$ of the respondents. Wholemeal bread was consumed much less frequently, with $90.2 \%$ of the respondents consuming it only once a week or not at all. White rice was eaten at least once a week by $97.7 \%$, while buckwheat-by $71.9 \%$ of the respondents. Among the least popular cereal products were buckwheat and wholemeal bread. One out of five young football players did not eat these products at all. The consumption of fried foods at least once a week was declared by $95.5 \%$ of the respondents (Fig. 5). Butter was the most frequently consumed fat, included in the diet at least once a day by $56.3 \%$ of the respondents. Lard was the least frequently consumed fat and $80.5 \%$ of the respondents never included it in their nutrition. Milk was the most common dairy product (Fig. 5). It was consumed at least once a day by $52.8 \%$ of the respondents. Fermented dairy products were slightly less common, with $34.9 \%$ of the respondents eating them once a day. From $2.3 \%$ to $4.5 \%$ of the respondents declared no consumption of milk or dairy products. The most frequently eaten meat products were cold meats (with $39.3 \%$ of the respondents having them at least once a day). Consumption of white meat at least once a week was more common than that of red meat $(92.1 \%$ vs. $88.5 \%$, respectively). Consumption of fish at the same frequency was declared by $92 \%$, and that of eggs was declared by $98.9 \%$ of the respondents. As for the consumption of fruits and vegetables, as well as juices produced thereof, $58.6 \%$ of the respondents included fruits in their diet several times a week, while $6.3 \%$ less respondents consumed vegetables. Consumption of fruit juices once daily or more often was declared by $22.7 \%$ of the young football players. Vegetable juices were much less popular-consumed by $6.8 \%$ of the respondents. Mineral water was the most frequently drunk beverage. As many as $80.9 \%$ of the respondents consumed it once daily or more often. However, 6.7\%

Table 1 A hierarchical list of food eaten between meals.

\begin{tabular}{ll}
\hline Food eaten between meals & $\begin{array}{l}\text { Percentage of the respondents* } \\
(\%)\end{array}$ \\
\hline Fruits & 63 \\
Sweet snacks, candies, cookies, cakes, chocolate bars, bars, such as “cereal wafers" & 58 \\
No sweetened beverages or dairy desserts, yoghurt, cottage cheese, milk & 49 \\
Sweetened beverages and dairy desserts, cream cheese, sweetened milk drinks, flavored milk & 48 \\
Vegetables & 25 \\
Salty snacks, crackers, breadsticks, potato chips, French fries & 20 \\
Nuts, almonds, seeds, pits & 17 \\
\hline
\end{tabular}

\footnotetext{
*Respondents could select more than one answer.
} 

Practicing Football in a Sports Club in Bydgoszcz, Poland

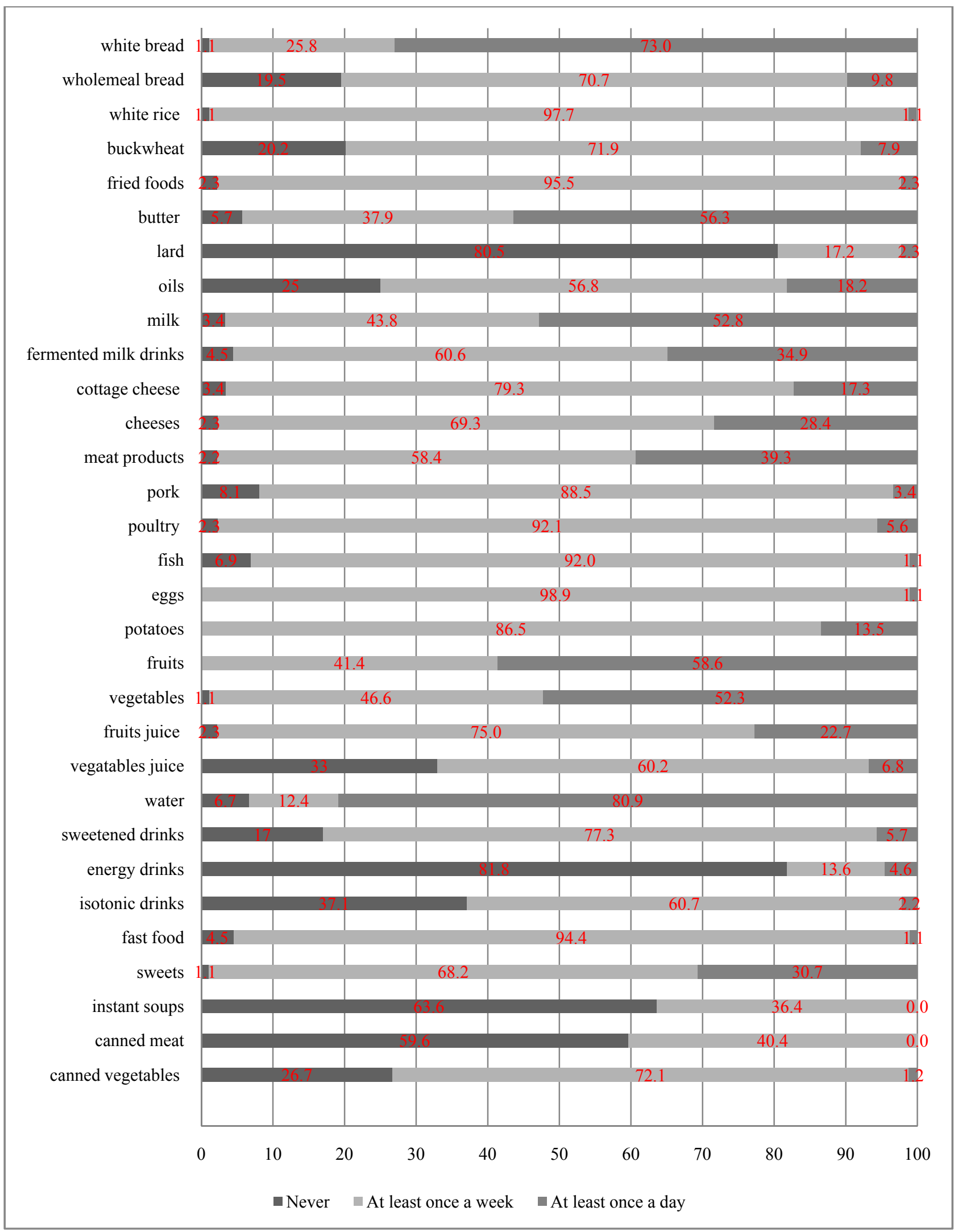

Fig. 5 Frequency of consumption of food products. 


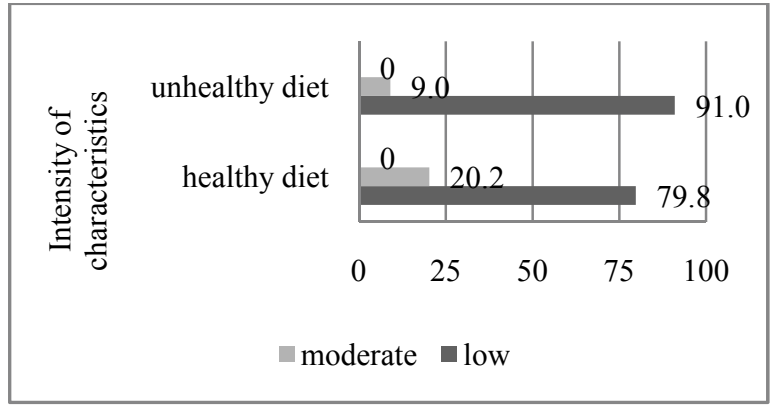

Fig. 6 Characteristics of healthy and unhealthy diet.

of the respondents declared not drinking mineral water at all. Sweet beverages were included in the diet once a week by $77.3 \%$, while once a day or more often — by $5.7 \%$ of the respondents. Energy drinks were consumed once a day by $4.6 \%$ and several times a week by $13.6 \%$ of the respondents. Isotonic drinks were never consumed by $37.1 \%$ of the respondents, while $60.7 \%$ of them declared consuming such drinks at least once a week. As regards the consumption of processed products, e.g., fast food, $94.4 \%$ of the respondents included them in their diet at least once a week. Another investigated product were sweets. Among the surveyed players, $30.7 \%$ ate sweets at least once a day, and almost all respondents ate sweets at least once a week. Instant soups were never consumed by $63.6 \%$ and canned meats were never consumed by $59.6 \%$ of the respondents. Canned vegetables were eaten much more frequently; only $26.7 \%$ of the respondents did not include them in their diet. Analysis of dietary habits in young football players demonstrated low and moderate intensity of the characteristics of unhealthy diet in $91 \%$ and $9 \%$ respondents, respectively. On the other hand, low and moderate intensity of the characteristics of healthy diet was identified in $79.8 \%$ and $20.2 \%$ of the respondents, respectively. No high intensity of the characteristics of both healthy and unhealthy diet were found in the surveyed group (Fig. 6).

Nutrition in children and adolescents practicing sports is more complicated than in adults, as it must take into account the increased demand for energy and nutrients typical of the appropriate sport discipline, satisfying the developmental requirements in adolescence, as well as the different metabolism in children compared to adults [22-24]. Regular consumption of five meals per day and maintaining the proper intervals between them allows an optimal distribution of energy throughout the day. Skipping meals should be avoided to ensure a constant supply of energy for the young player during the day, which should help to prevent reduction in the effectiveness of training and cognitive processes [25-28].

Our study demonstrated that only $30 \%$ of the respondents ate five meals per day, while $60 \%$ of the subject ate four meals per day. In a study conducted in a group of swimmers (12 14 years of age), consumption of 4 5 meals per day was declared by only $20 \%$ of the respondents [29]. However, in a study conducted in the Krakow Sport Champions School (Krakow, Poland), consumption of five meals per day was declared by nearly $45 \%$ of the respondents [25]. Results similar to those obtained in our study were reported in a group of adult athletes practicing football [30]. Five meals per the day were consumed by $25 \%$ of players of a 4 th league team and $30 \%$ of players of a 6th league team, while four meals per the day were consumed by $45 \%$ and $30 \%$ of players, respectively. Moreover, out study demonstrated that only approximately $16 \%$ of the young players had meals at fixed times. In this respect, our results do not deviate substantially from those obtained by Kopeć et al. in a group of adult athletes, approximately $20 \%$ of whom had meals at fixed times of the day [30]. Having snacks between meals is a negative eating habit that can be a result of improper planning of meals during the day and the lack of fact-based knowledge about nutrition and intake of fluids before, during and after training or sports events. Acquiring and implementation of the knowledge about nutrition in this particular period of time for a person practicing sports is extremely important because of the need to provide the appropriate quantity of nutrients and water required to keep the body at a high level of ability and capacity for training and performance during sports events, as well 
as improved regeneration after maximum physical effort $[15,22,31]$. The most common snacks in the investigated group of young sportsmen were fruits and sweets. Sweets, consumed by almost all respondents at least once a week, with more than $30 \%$ consuming them every day, exert adverse impact on the young organism due to the high content of simple sugars and trans fatty acids. Although fruits contain a high quantity of simple sugars, they also increase the supply of antioxidants that are essential in sports nutrition due to the phenomenon of oxidative stress associated with intense physical effort [29, 32-34]. Cereal products are the principal source of energy used by athletes during physical effort. Athletes, including children and adolescents practicing sports, should eat cereal products made from wholemeal flour that provides B vitamins and a higher quantity of fiber and allows a better use of energy during effort and restoration of glycogen [35]. Before and after training and sports events, it is recommended to consume white bread, rice and small groats to avoid problems with the digestive system. Approximately $75 \%$ of the young players surveyed in this study ate white bread at least once a day, and $98 \%$ of them ate white rice at least once a week. In the study by Gacek [36], almost $60 \%$ of boys deliberately chose bread made from purified flour. However, the frequency of consumption of white bread among adult athletes reveals a proportion opposite to that reported for young athletes. White bread was eaten every day by $25 \%$ of adult football players and approximately $10 \%$ of rugby league players [37]. Analysis of the consumption of dark bread and groats demonstrated that one in five boys from every surveyed group never ate wholemeal cereal products. This study revealed that boys practicing football had milk and dairy products too rarely. These products should be consumed at least once a day and preferably $3 \sim 4$ times per day due to their content of complete protein and, above all, calcium with the highest biological availability, responsible for the correct bone mineralization. In the study by Gacek [36], the frequency of consumption of milk and dairy products was slightly higher. The products were consumed every day by $77 \%$ of the surveyed boys [36]. However, in another study, milk and yoghurt were consumed "often" by less than $30 \%$ of rugby league players, while none of them ate cheese at the same frequency [37]. A study conducted in adult football players demonstrated that the consumption of milk and dairy products was much lower in comparison with that in young athletes: consumption of milk and milk beverages every day was declared by only $30 \%$ of the respondents, while that of hard cheese was declared by $5 \%$. No subject ate white cheese every day, while only $10 \sim 15 \%$ of the respondents ate white cheese 3 6 times per week [30]. Cold meats and meat products, due to their high degree of processing and a high content of salt and preservatives, are not recommended in the diet of young athletes. However, our study revealed the consumption of these products is quite common. Almost $40 \%$ of the young players ate them every day. In a 4th league football team, $15 \%$ and $35 \%$ of adult players ate cold meats and meat products, respectively, every day [30], while among young modern pentathlon players, less than $5 \%$ of them ate cold meats 5 or more times per week. As reported in the study, young athletes ate poultry meat much more frequently than pork compared to adult athletes [33]. The consumption of fish in sportsmen is very beneficial, as fish are a source of complete protein and contain omega-3 unsaturated fatty acids, Vitamins $\mathrm{D}_{3}$ and $\mathrm{A}$, iron and iodine. Earlier studies demonstrated that fish were included in diet $1 \sim 2$ times per week by $57 \%$ of boys [37] and $25 \%$ of players in athletics [28]. Fish were occasionally eaten by $9 \%$ and never by $90 \%$ of rugby players [37]. Much lower fish consumption was shown in a study by Coutinho in which fish were eaten $2 \sim 4$ times per week by approximately $10 \%$ of young players [33]. In our study, fish consumption at least once a week was declared by $92 \%$ of young players, which is a beneficial habit in the light of other studies.

The results obtained in our study allow a conclusion 
that young athletes eat fruits and vegetables too rarely. This is a very unfavorable habit as these products contain significant amounts of fiber, minerals and vitamins, including those of antioxidant action, and additionally fruits are a rich source of medium- and low-glycemic carbohydrates. Young people practicing sports should consume three portions of vegetables and two portions of fruits per day, whereas only approximately $50 \%$ of the surveyed young players ate them once a day. The content of fruits and vegetables in the diet of the adolescents from the Krakow Sport Champions School (Krakow, Poland) was insufficient as well. Less than $20 \%$ and $36 \%$ of boys ate several portions of vegetables and fruits, respectively, during the day [25]. In the study by Couthinho, it was shown that only $20 \%$ of young sportsmen ate these products five or more times per week [33], while none of the surveyed rugby players ate them "often" [37]. Fruits and vegetables are consumed much less frequently by adult athletes, as only $5 \%$ of players of a 4 th league team and $15 \%$ of players of a 6 th league team included them in their daily diet [28]. The surveyed young sportsmen consumed fluids of different nutritional value and taste at different frequencies. Our study demonstrated that low- and medium-mineralized water was the most common, drunk at least once a day by more than $80 \%$ of the young players. Concurrently, $23 \%$ and $7 \%$ of the boys drank fruit juices and vegetable juices, respectively, at the same frequency. A study concerning fluid intake conducted in a group of junior footballers by Gacek [36] demonstrated that the players drank water every day and drank fruit and vegetable juices several time per week. Couthinho et al. [33] reported results similar to ours in terms of fluid intake. Approximately $25 \%$ of young players consumed juices five or more times per week. Indices of healthy and unhealthy diet proposed here may be an innovative marker for the evaluation of nutrition quality in young sportsmen. Our study showed that low intensity of the characteristics of both healthy and unhealthy diet prevailed. In the investigated group, $20.2 \%$ and $9 \%$ of the respondents demonstrated moderate intensity of the characteristics of healthy and unhealthy diet, respectively. Therefore, we can conclude that the diet of young football players contained food products from both the recommended and the not recommended groups. The obtained detailed results and diet indices are another reason to bring the attention of parents, guardians, trainers, schools directors and young sportsmen themselves to the importance of varied and balanced nutrition in the entire chain of building career in sports, taking into account not only the needs arising from the practiced sports discipline, but also the proper physical and mental development and the different metabolism in the developmental age in comparison with adult age.

\section{Conclusions}

Following points can be drawn from the study:

(1) Attention should be paid to the consumption of proper meals and drinks by young sportsmen before, during and after training or sports events;

(2) The reported improper aspects of the nutrition and eating habits of young footballers indicate the need for a systematic nutritional education based on scientific evidence, provided to the young players themselves, as well as their parents or legal guardians, trainers, teachers, school directors, school caterers, school shop owners and boarding managers, particularly in sport schools.

\section{References}

[1] Department of Youth Football Association. 2010. "The Organization of Training of Children and Youth Football in Poland." Department of Training Polish Football Association. Accessed August 15, 2016. http://www.pzpn.pl.

[2] Cuenca-Garcia, M., Ortego, F. B., and Ruiz, J. R. 2014. "More Physically Active and Leaner Adolescents Have Higher Energy Intake.” J. Padiatr. 164 (1): 159-66.

[3] Martinez, J., Lowenstein, M. K., and Montague, A. 1993. "Nutrition and Substance Use in the Adolescent Male Football Player." International Pediatrics 8: 435-9.

[4] Kolmaga, A., Cold-Walendzik, E., Rusińska, A., Rychłowska, E., and Trafalska, E. 2011. "Disorders 
Nutritional Status of Children Completing Primary School in Lodz and the Quality of the Skeleton. Part I: Assessment of Anthropometric Parameters, Subjective Physical Activity and Dental Health." Hyg. Pub. Health 46 (1): 64-70.

[5] Dietitians of Canada, the American Dietetic Association and the American College of Sports Medicine. 2000. "Dietitians of Canada, the American Dietetic Association and the American College of Sports Medicine Joint Position Statement: Nutrition and Athletic Performance." Can. J. Diet. Pract. Rest. 61: 176-92.

[6] Montfort -Steiger, V., and Williams, C. A. 2007. "Carbohydrate Intake Considerations for Young Athletes." Journal of Sports Science and Medicine 6: 343-52.

[7] Murat, K., Zurek, M., Michno, M., and Michalski, C. 2012. "The Impact of Diet on Different Carbohydrate Levels on Human Metabolism at Rest and Exercise." Physical Activity People of All Ages 16: 103-11.

[8] Jarosz, M., ed. 2012. Nutrition Standards for the Polish Population-Amendment. Warsaw: Institute of Nutrition and Food.

[9] Maughan, R. J., and Burke, L. M. 2002. Handbook of Sports Medicine and Science Sports Nutrition. Oxford: Blackwell Science.

[10] Malczewska, J. 2013. "Fundamentals of Rational Nutrition and Fluid Replacement in Training Juvenile Footballers." Official Website of Polish Football Association. Accessed December 29, 2013. http://www.pzpn.pl/inexphp/Federacja/Trenerzy/Materiał y-Szkoleniowe/Zywienie-mlodych-pilkarzy-Jadwiga-Mal czewska.

[11] Purcell, L. K. 2013. "Sport Nutrition for Young Athletes, Canadian Pediatric Society, Pediatric Sports Exercise Medicine Section." Pediatr. Child Health 18 (4): 200-2.

[12] Figurska-Ciura, D., Bartnik, J., Biernat, J., and Bronowska, M. 2014. "Qualitative and Quantitative Assessment of the Impact of Nutrition Education for the Intake of Selected Nutrients Young Players." Probl. Hig. Epidemiol. 95: 471-6.

[13] Rowland, T. 2011. "Fluid Replacement Requirements for Child Athletes." Sports Med. 41 (4): 279-88.

[14] Wilk, B., Yuxiu, H., and Bar-Or, O. 2002. "Effect of Body Hypohydration on Aerobic Performance of Boys Who Exercise in the Heat." Med. Sci. Sports Exerc. 34 (5): S48.

[15] Benardot, D. 2000. Nutrition for Serious Athletes: An Advanced Guide Foods, Fluids and Supplements for Training and Performance. Champaign: Human Kinetics.

[16] Burke, L. M. 2008. "A Food Pyramid for Swiss Athletes." International Journal of Sport Nutrition Exercise Metabolism 18 (4): 430-7.

[17] Jarosz, M. ed. 2008. The Principles of Proper Nutrition of Children and Youth as Well as Tips for a Healthy Lifestyle.
Warsaw: Institute of Nutrition and Food.

[18] Brooks, G. A., Henderson, G. C., Hashimoto, T., Mau, T., Fattor, J. A., Horning, M. A., et al. 2006. "Lactic Acid Accumulation in an Advantage/Disadvantage during Muscle Activity." Journal of Applied Physiology 100 (6): 1410-4.

[19] Roetert, P. E. 2004. "Proper Nutrition for Young Athletes." National Strength and Conditioning Association 26 (3): 25-6.

[20] Kulaga, Z., Różdżyńska, A., Palczewska, I., Zajączkowska, M., Zwolińska, D., Krynicki, T., et al. 2010. "Centile Charts: Height, Weight and Body Mass Index in Children and Adolescents in Poland-The Results of OLAF." Pediatrics 7: 690-700.

[21] Jeżewsk-Zychowicz, M., Gawęcki, J., Wądołowska, J., Czarnocińska, J., Galiński, G., Kołłajtis-Dołowy, A., et al. 2014. "Questionnaire for the Study of Views and Eating Habits for People Aged 16 to 65, Version 1.1-A Questionnaire Administered by an Interviewer-Investigator." In A Questionnaire to Study the Views and Eating Habits and the Procedure for Processing Data, edited by Gawęcki, J., and Committee of Science of Human Nutrition Polish Academy of Sciences, Warsaw. Accessed March 20, 2014. http://www.knozc.pan.pl/.

[22] Nemet, D., and Eliakim, A. 2009. "Pediatric Sports Nutrition: An Update." Current Opinion in Clinical, Nutrition and Metabolic Care 12: 304-9.

[23] Bonci, L. 2010. "Sports Nutrition for Young Athletes." Pediatric Annals 39 (5): 300-5.

[24] Purcell, L. K. 2013. "Sport Nutrition for Young Athletes." Paediatr. Child Health 18 (2): 200-2.

[25] Gacek, M. 2007. "Knowledge and Behavior Habits of Young People in Sport in the School Athletic in Krakow, Rocz." National Institute of Hygiene 58 (4): 641-8.

[26] Petrie, H. J., Stover, E. A., and Horswill, C. A. 2004. "Nutritional Concerns for the Child and Adolescent Competitor." Nutrition 20: 620-31.

[27] P.E Roetert., Proper nutrition for young athletes, National Strength and Conditioning Association (2004); 26 (3): 25-26.

[28] Leonkiewicz, M., Gacek, M., and Frączek, B. 2015. "Knowledge and Nutritional Behavior of Teenagers in Sport-The Need for Education." In The Importance of Rational Nutrition in Health Education. Warszawa: WSIIZ, 71-85.

[29] Zabrocki, R., and Kaczynski, R. 2012. "Rating Dietary Behaviors of Youth Sports Exercise, for Example Swimming." Bromatologia and Toxicological Chemistry 3: 729-32.

[30] Kopec, A., Nowicka, E., Klaja, A., and Leszczyńska, T. 2013. "Frequency of Consumption of Selected Groups of 

Practicing Football in a Sports Club in Bydgoszcz, Poland

Food Products for Athletes Trainees Football.” Probl. Hig. Epidemiol. 94 (1): 151-7.

[31] Benjamin, H. 2008. "Proper Hydration Can Help Prevent Heat-Related Illnesses in Young Athletes." AAP News. Accessed August 15, 2014. http://www.illinoisaap.org/ Newsletter/SportsMed-Summer08.pdf.

[32] Szczepańska, B., Malczewska-Lenczowska, J., and Gajewski, J. 2007. "Nutritional Habits of Junior High School Students from the Warsaw School Athletic." Human Nutrition and Metabolism 34: 578-86.

[33] Coutinho, L. A., Porto, C. P., and Pierucci, A. P. 2016. "Critical Evaluation of Food Intake and Energy Balance in Young Modern Pentathlon Athletes: A Cross-Sectional Study" Journal of the International Society of Sport Nutrition 2: 13-5.

[34] Fiedor, M. 2005. "Analysis and Evaluation of the Diet of
Young People Representing Staff Podkarpackie Province in Athletics." Annales Universitatis Mariae Curie-Sklodowska Lublin-Polonia 60 (Suppl. 16): 449-52.

[35] Montfort-Steiger, V., and Williams, C. A. 2007. "Carbohydrate Intake Considerations for Young Athletes." J. Sports Sci. Med. 6: 343-52

[36] Gacek, M. 2015. “Association between Self-Efficacy and Dietary Behaviours of American Football Players in the Polish Clubs in the Light of Dietary Recommendations for Athletes." Roczniki Państwowe Zakładów Higieny 66 (4): 361-6.

[37] Alaunyte, I., Perry, J., and Aubrey, T. 2015. "Nutritional Knowledge and Eating Habits of Professional Rugby League Players: Does Knowledge Translate into Practice?." Journal of the International Society of Sports Nutrition 12: 18. 